\title{
Updated Evaluation of the Safety, Efficacy and Tolerability of Pirfenidone in the Treatment of Idiopathic Pulmonary Fibrosis
}

This article was published in the following Dove Press journal:

Drug, Healthcare and Patient Safety

\author{
Swati Gulati' \\ Tracy R Luckhardt ${ }^{1,2}$ \\ 'Division of Pulmonary, Allergy, and \\ Critical Care Medicine, University of \\ Alabama at Birmingham, Birmingham, AL, \\ USA; ${ }^{2}$ Department of Medicine, \\ University of Alabama at Birmingham, \\ Birmingham, AL, USA
}

\begin{abstract}
Idiopathic Pulmonary Fibrosis (IPF) is a chronic fibrotic disease characterized by a progressive decline in lung function with a median survival of 3-5 years after diagnosis. The course of disease is highly variable and unpredictable, often punctuated by episodes of acute respiratory failure, known as acute exacerbations. The incidence of IPF is on the rise due to the aging population, as age is the most important risk factor for this disease. Pirfenidone and nintedanib are the two anti-fibrotic drugs approved for IPF which have shown reduction in lung function decline. This review will discuss the efficacy, safety and tolerability profile of pirfenidone from clinical trials and the real-world clinical experience. Pirfenidone reduces the decline in lung function and improves progression-free survival in patients with IPF. It is generally well tolerated with the most common side effects being gastrointestinal and phototoxicity.
\end{abstract}

Keywords: Pirfenidone, idiopathic pulmonary fibrosis, efficacy, safety, tolerability

\section{Introduction}

Idiopathic Pulmonary Fibrosis (IPF) is a chronic fibrotic disease characterized by a progressive decline in lung function from irreversible destruction of lung architecture, subsequently culminating in respiratory failure. ${ }^{1}$ It usually occurs in individuals older than 50 years and its incidence remarkably increases with age. ${ }^{1,2}$ Median survival is 3-5 years following diagnosis, however, course of the disease is unpredictable and highly variable. ${ }^{3}$ Patients will sometimes experience a period of disease stability followed by sudden onset of acute respiratory failure, also known as an exacerbation. IPF exacerbations markedly shorten the median survival to 3-4 months and precede almost half of deaths in patients with IPF. ${ }^{4}$

Pirfenidone and nintedanib are the two anti-fibrotic drugs approved for treatment of IPF. $^{5-7}$ Pirfenidone was the first licensed therapy for IPF and was approved by the European Medicines Agency (EMA) in 2011, followed by The US Food and Drug Administration (FDA) approval in 2014. Pirfenidone is an orally available drug known to mediate its anti-inflammatory and anti-fibrotic effects through modulation of cytokines and growth factors, although the precise mechanism of its action remains unclear. ${ }^{8,9}$ Treatment with pirfenidone has been shown to reduce the rate of decline in lung function, improve progression-free survival and also reduces all-cause mortality at 1 year. ${ }^{6,10,11}$

This review will discuss and summarize the efficacy, tolerability and safety profile of pirfenidone based on clinical trials and real-world clinical experience to date.
Correspondence: Swati Gulati

Division of Pulmonary, Allergy, and

Critical Care Medicine, University of

Alabama at Birmingham, 1900 University

Blvd THT 54IE, Birmingham, AL 35294-

2180, USA

Tel +I 2059756376

$\mathrm{Fax}+\mid 205934$ |72।

Email sgulati@uabmc.edu 


\section{Efficacy of Pirfenidone in Patients with IPF \\ Clinical Trials}

The first Phase II double-blind placebo-controlled trial evaluated the efficacy of Pirfenidone $(1800 \mathrm{mg} /$ day) as compared to placebo in 109 patients. ${ }^{11}$ Pirfenidone group showed reduction in vital capacity decline as compared to the placebo group $(-30 \mathrm{~mL}$ vs $-130 \mathrm{~mL}, \mathrm{p}=0.032)$. However, this trial was prematurely aborted in favor of Pirfenidone due to an increased number of IPF exacerbations in the placebo group (14\% vs $0 \%, p=0.003) .{ }^{11}$ Following the encouraging results of this trial, the first Phase III, placebo-controlled, randomized clinical trial evaluated pirfenidone at high $(1800 \mathrm{mg} / \mathrm{d})$ and low $(1200 \mathrm{mg} / \mathrm{d})$ doses as compared to placebo in 275 patients with IPF. The trial showed that patients in the highdose group had a reduction in vital capacity decline as compared to placebo $(-90 \mathrm{~mL}$ vs $-160 \mathrm{~mL}, \mathrm{p}=0.04)$ and had an improved progression-free survival $(\mathrm{p}=0.03) .{ }^{12}$

Since then, pirfenidone has been evaluated in three multinational, randomized, and placebo-controlled trials, documenting its efficacy in preserving lung function and conferring a progression free survival benefit. Of these 3 trials, CAPACITY 004 and CPAPCITY 006 (Clinical Studies Assessing Pirfenidone in idiopathic pulmonary fibrosis: Research of Efficacy and Safety Outcomes) were two concurrent trials completed in 2010 leading to pirfenidone approval for use in IPF patients in Europe. ${ }^{5}$ ASCEND (Assessment of Pirfenidone to Confirm Efficacy and Safety in Idiopathic Pulmonary Fibrosis) study was the third trial specifically requested by US FDA, which was completed in $2014 .^{6}$

CAPACITY trials assessed pirfenidone $(2073 \mathrm{mg} /$ day) in a total of 770 patients with IPF with a forced vital capacity (FVC) of $\geqslant 50 \%$ predicted and diffusing capacity for carbon monoxide (DLCO) of $\geqslant 35 \%$ predicted. The primary endpoint was change in $\mathrm{FVC} \%$ predicted from baseline to week 72. Pirfenidone significantly reduced the decline in FVC \% predicted from baseline over 72 weeks as compared to placebo in the CAPACITY 004 trial ( $-8 \%$ vs $-12.4 \%$, respectively, $\mathrm{p}=0.001)$. CAPACITY 006 also recorded a significant difference in $\mathrm{FVC} \%$ predicted up to week 48 in pirfenidone group, although this difference was not maintained at week $72 .{ }^{5}$

Pre-specified pooled data analysis from both studies showed a significant treatment effect for pirfenidone, with mean change in $\mathrm{FVC} \%$ predicted over time of $-8.5 \%$ for pirfenidone vs $-11.0 \%$ for placebo $(\mathrm{p}=0.005)$. Pirfenidone group also showed a positive treatment effect vs placebo for secondary end points of progression-free survival (defined as time to confirmed $\geq 10 \%$ decline in FVC $\%$ predicted, $\geq 15 \%$ decline in diffusing capacity of the lung carbon monoxide $\%$ predicted, or death), categorical decline in $\mathrm{FVC} \geq 10 \%$ and the 6-min walk test (6MWT) distance. Although the CAPACITY study was not powered for mortality analysis, a pooled analysis did show a non-statistically significant trend towards lower all-cause mortality at week 72 in the pirfenidone group compared to the placebo group $(4.4 \%$ vs $7.9 \%$, respectively, $\mathrm{p}=0.315){ }^{5}$

Since the primary end point of predicted FVC \% change from baseline to week 72 was not met in CAPACITY 006 trial, US FDA requested another clinical trial to demonstrate the efficacy of Pirfenidone.

ASCEND trial then assessed pirfenidone (2073mg/day) in 555 IPF patients with FVC of $50-90 \%$ predicted and DLCO of $\geqslant 30 \%$ predicted. The pirfenidone group showed a significant reduction in primary-end point, which was the mean FVC decline at 52 weeks, as compared to placebo ( $253 \mathrm{~mL}$ vs $428 \mathrm{~mL}, \mathrm{p}<0.001$ ) and also reduced the relative risk of death or disease progression by $43 \%$ (confidence interval [CI], 0.43 to $0.77 ; \mathrm{p}<0.001)^{6}$

In a pre-specified analysis of the pooled population of all three trials (CAPACITY 004, CAPACITY006 AND ASCEND), pirfenidone reduced the risk of death at 1 year by $48 \%$ compared to placebo (HR $0.52,95 \%$ CI $0.31-0.87 ; \mathrm{p}<0.01$ ) and also reduced the risk of treatmentemergent death due to IPF at 1 year by $68 \%$ (HR 0.32 ; 95\% CI 0.14-0.76; $\mathrm{p}=0.006) .{ }^{6,10}$

Similarly, pooled data analysis from these trials by Noble et al showed that pirfenidone reduced the proportion of patients with $\geqslant 10 \%$ decline in $\mathrm{FVC} \%$ predicted or death by $44 \%(95 \%$ CI 29.3-55.4\%) and increased the proportion of patients with no lung function decline by $59.3 \%$ (95\% CI 29-96.8\%). ${ }^{13}$

Longitudinal FVC data from these three trials have demonstrated that even in patients who had a $10 \%$ decline in $\mathrm{FVC} \%$ during treatment, continued treatment with pirfenidone resulted in a lower risk of subsequent $\mathrm{FVC}$ decline or death as compared to placebo. (5.9\% vs $27.9 \%$, respectively, $\mathrm{p}=0.009){ }^{14}$

\section{Long-Term Observational Studies \\ RECAP Study (an Open-Label Study of the} Long-Term Safety of Pirfenidone in Patients with Idiopathic Pulmonary Fibrosis)

RECAP was an open-label roll-over study evaluating the long-term safety of pirfenidone $2043 \mathrm{mg}$ /day in patients 
who completed the CAPACITY and ASCEND trials. ${ }^{15}$ Of the 1058 patients who entered RECAP from both the trials, $40.4 \%$ completed the study at the time of analysis in 2015 . Median duration of Pirfenidone was 88 weeks (ranging from $>0$ to 349 weeks) with a mean dose of $2091.1 \mathrm{mg} /$ day. In patients who completed CAPACITY trials and entered RECAP, the mean change in FVC \% predicted from RECAP baseline at 180 weeks was $-9.6 \%$. Median on-treatment survival from the first pirfenidone dose was 77.2 months. ${ }^{15}$ Efficacy data in terms of FVC decline was not recorded in patients from ASCEND trial.

In real-world clinical practice, sometimes there is hesitation in starting anti-fibrotics in patients with advanced disease. Costabel et al recently analyzed data from RECAP study to evaluate and compare the efficacy of pirfenidone in IPF patients across different categories of disease severity. ${ }^{16}$ Patients were categorized according to baseline lung function at the time of entry into the RECAP study: more advanced (FVC\% predicted $<50 \%$ and/or DLco $<35 \%, \mathrm{n}=189$ ) and less advanced (FVC\% predicted $\geq 50 \%$ and/or DLco $\geq 35 \%, n=409$ ). Long-term treatment with pirfenidone resulted in a similar rate of FVC percent decline and safety profile in patients with more advanced and less advanced IPF. However, the discontinuation rate was higher for patients with more advanced disease. ${ }^{16}$ This study supports considering anti-fibrotics in patients who are diagnosed with IPF at an advanced stage.

\section{Results from the Czech IPF Registry}

Zurkova et al evaluated the overall 2- and 5-year survival and lung function decline in 601 patients from Czeck IPF registry who were diagnosed with IPF between 2012 and $2017 .{ }^{17}$ Of 601 patients, $63.7 \%$ of patients received pirfenidone treatment and the rest were not on any anti-fibrotic. The pirfenidone treated group had overall longer survival at 12, 24 and 60 months as compared to those treated with no antifibrotics. More than half of the patients $(55.9 \%)$ were still alive at the end of 5 years in the pirfenidone group as compared to $31.5 \%$ in the no antifibrotic group $(\mathrm{p}=0.002)$. Patients in the pirfenidone group also showed a non- statistically significant trend towards the reduction in rate of FVC \% decline at 6, 12 and 24 months as compared to the no antifibrotic group. ${ }^{17}$

\section{Single Center Studies}

Since its approval for use in IPF patients, various centers from different countries have published their real-world experience with Pirfenidone in terms of efficacy, safety and tolerability. The overall trend in efficacy has been consistent with the findings from the clinical trials and no significant new trends were noted. The findings from all these single-center trials to date are summarized in Table 1.

\section{Pirfenidone and Acute IPF Exacerbations}

Acute exacerbation of IPF (AE-IPF) is defined as an unexplained worsening of dyspnea in the past 30 days in patients with previous or concurrent diagnosis of IPF, a high-resolution computed tomography with evidence of new bilateral ground-glass opacities or consolidation, and exclusion of alternative causes. ${ }^{1}$

AE-IPF has an annual incidence of up to $20 \%$ and is typically associated with a median survival of 3 months or less. ${ }^{4,18,19}$ Acute exacerbation of IPF accounts for over half of all hospital admissions and can account for nearly $40 \%$ of all deaths in IPF patients. ${ }^{20}$

No treatments have been shown to be effective in the treatment of acute exacerbations. Patients are usually managed with supplemental oxygen, antibiotics, high doses of corticosteroids. $^{21}$ Mechanical ventilation is not recommended, however, a subset of patients have shown to benefit from non-invasive ventilation. ${ }^{22,23}$ The role of antifibrotics in management or prevention of IPF exacerbation remains largely unexplored.

Pirfenidone has been shown to lower the risk of respiratory-related hospitalization when compared to placebo over 1 year in a pooled analysis of all three phase -3 trials $(7 \%$ vs $12 \%, p=0.001) .{ }^{24}$ While this study could be inferred in favor of pirfendone to reduce mortality associated with acute exacerbations, its role in acute exacerbation remains largely uninvestigated and unclear. In the preapproval era, a small Phase 2 trial of 107 patients evaluating the efficacy of pirfenidone showed a numerically small but statistically significant reduction in acute exacerbation in patients receiving pirfenidone, but these results were not replicated in a larger 275 -subject trial. ${ }^{11,12}$

One single center retrospective study of 47 patients with AE-IPF showed that patients who were on pirfenidone prior to the onset of exacerbation $(n=9)$ had improved 3-month survival as compared to patients who were not on pirfenidone $(n=18)(55 \%$ vs $34 \%, p=0.042) .^{25}$ The treatment protocol in this study also used recombinant human thrombomodulin which has shown to be beneficial for AE-IPF and could be a confounding factor in the analysis. $^{26}$ Although encouraging, but the results of this study need to be validated in larger cohorts. 


\begin{tabular}{|c|c|c|c|c|c|c|c|c|c|}
\hline 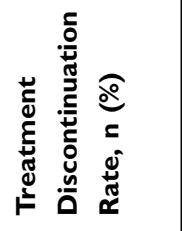 & $\begin{array}{l}\stackrel{\circ}{\circ} \\
\stackrel{0}{\circ}\end{array}$ & 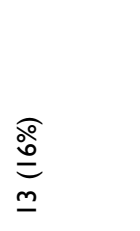 & 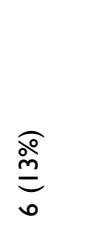 & 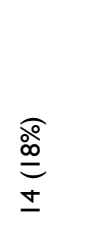 & 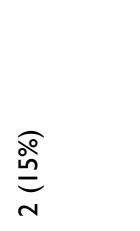 & 吕 & $\stackrel{\frac{0}{0}}{\stackrel{n}{6}}$ & 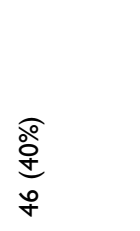 & 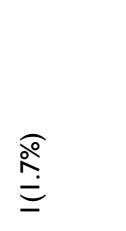 \\
\hline 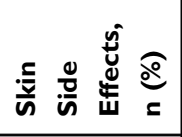 & $\S$ & $\S$ & $\begin{array}{l}\widehat{o} \\
\stackrel{0}{0} \\
\simeq\end{array}$ & 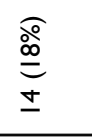 & 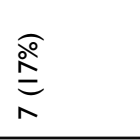 & 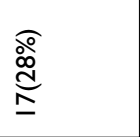 & $\stackrel{\circ}{\stackrel{\circ}{\circ}}$ & $=\stackrel{\substack{i 0_{0}^{\circ} \\
\infty}}{\infty}$ & \\
\hline 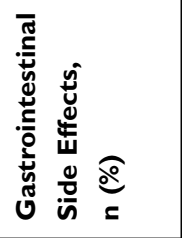 & $\S$ & $\S$ & 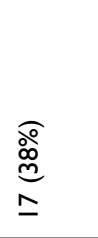 & $\begin{array}{l}\text { } \\
\stackrel{\circ}{0} \\
\stackrel{d}{d} \\
\underline{\infty}\end{array}$ & 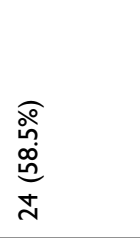 & 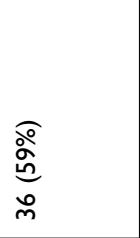 & 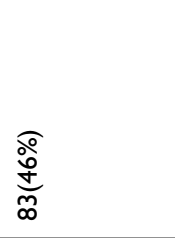 & 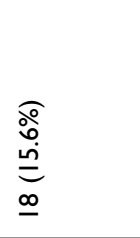 & 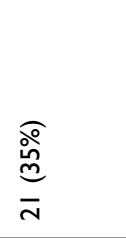 \\
\hline 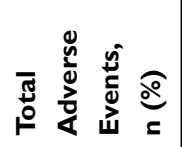 & 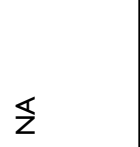 & $\S$ & $\S$ & 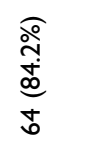 & 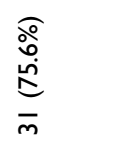 & 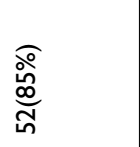 & 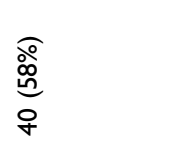 & 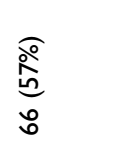 & $\begin{array}{l}\text { 号 } \\
\text { 总 } \\
\text { m }\end{array}$ \\
\hline 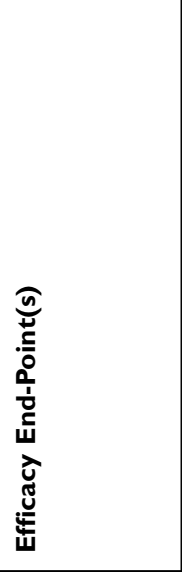 & 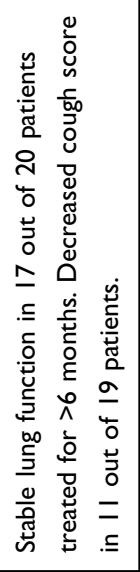 & 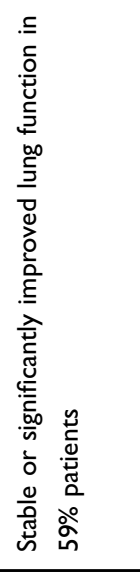 & 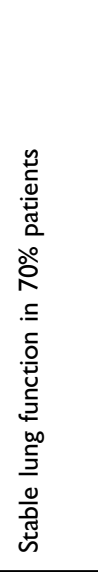 & 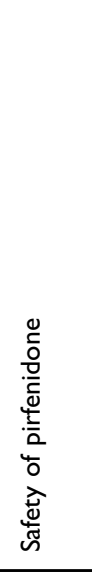 & 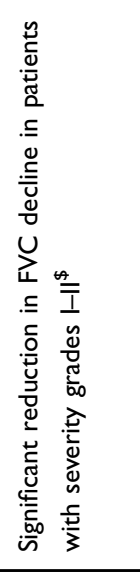 & 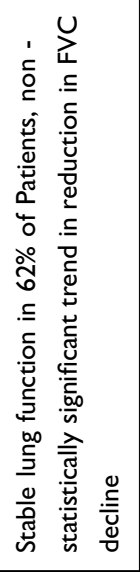 & 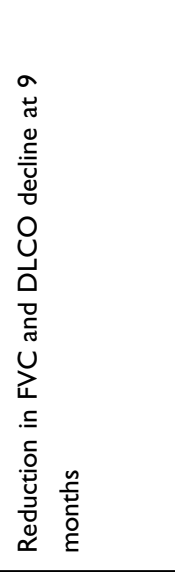 & 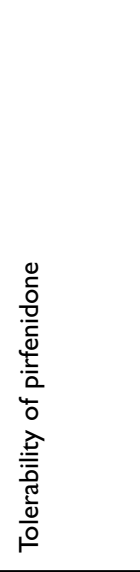 & 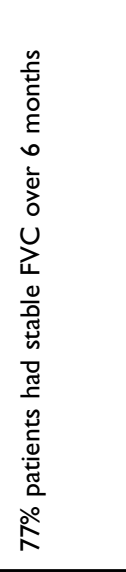 \\
\hline 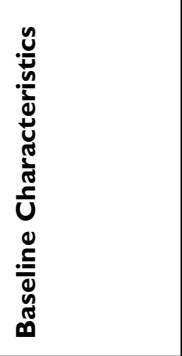 & 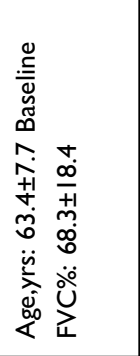 & 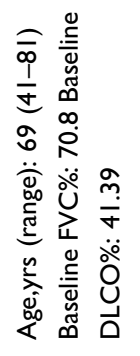 & 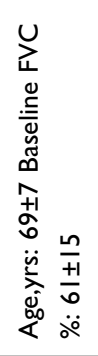 & 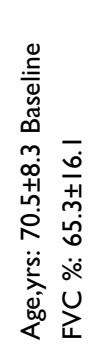 & 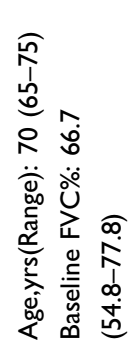 & 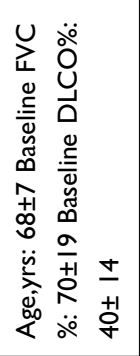 & 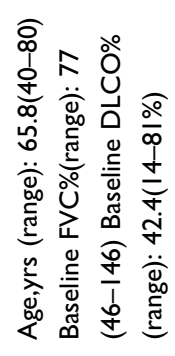 & 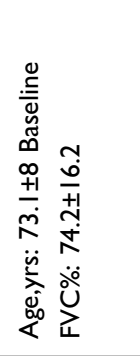 & 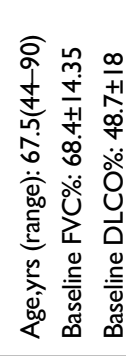 \\
\hline 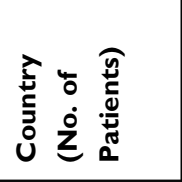 & 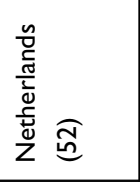 & 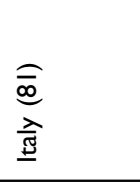 & 突 & 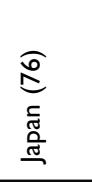 & 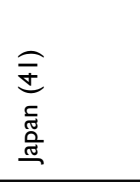 & 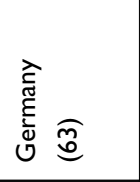 & 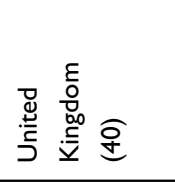 & 兽 & 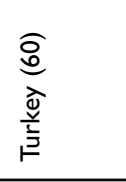 \\
\hline 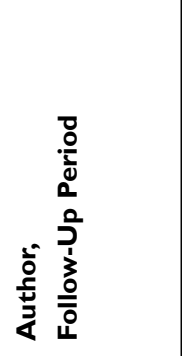 & 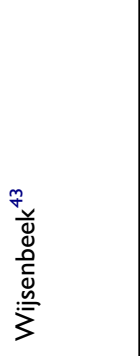 & 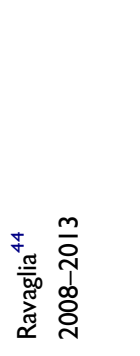 & 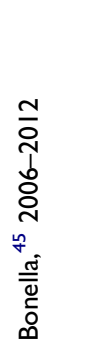 & 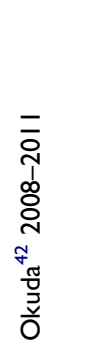 & 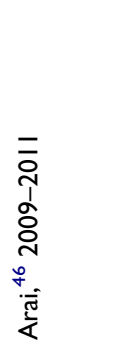 & 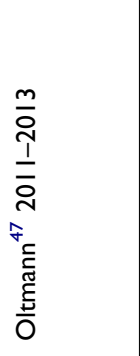 & 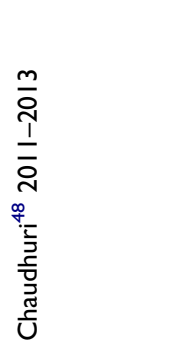 & 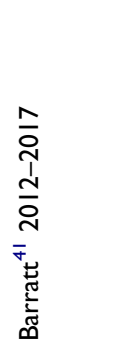 & 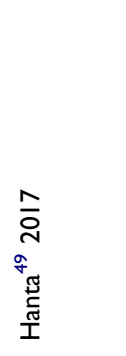 \\
\hline
\end{tabular}




\begin{tabular}{|c|c|c|c|}
\hline 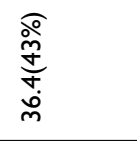 & $\begin{array}{l}\text { ๖. } \\
\text { ò } \\
\text { a }\end{array}$ & 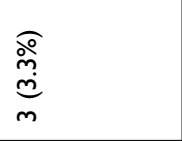 & $\begin{array}{l}\stackrel{0}{\stackrel{\circ}{0}} \\
\underline{\infty}\end{array}$ \\
\hline$\frac{\widehat{\circ}}{\frac{o}{m}}$ & $\infty \stackrel{\widehat{\circ}}{\stackrel{\infty}{\infty}}$ & $\begin{array}{l}\stackrel{\substack{\infty \\
ٍ}}{\simeq} \\
\underline{\infty}\end{array}$ & 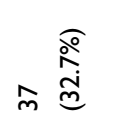 \\
\hline 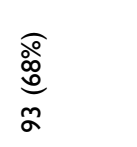 & $\begin{array}{l}\text { よ } \\
\stackrel{0}{\mathrm{~m}} \\
\stackrel{\mathrm{m}}{\underline{n}}\end{array}$ & 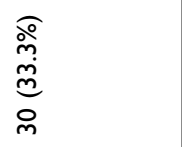 & 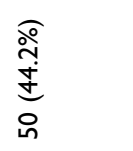 \\
\hline 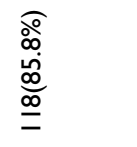 & $\S$ & $\Sigma$ & $\S$ \\
\hline 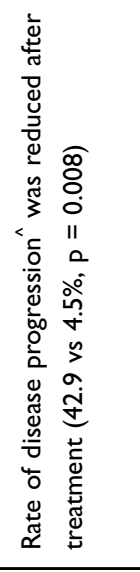 & 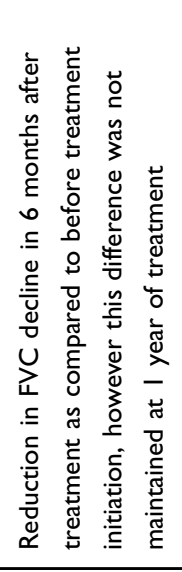 & 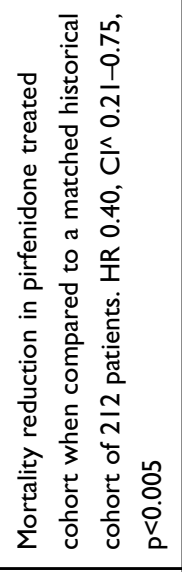 & 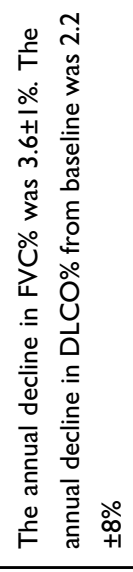 \\
\hline 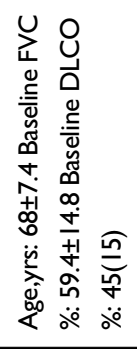 & 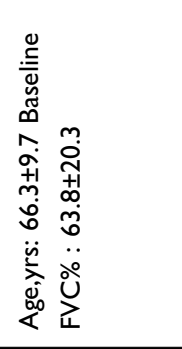 & 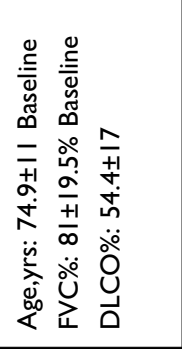 & 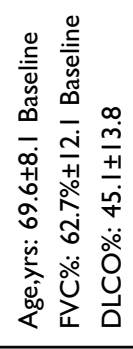 \\
\hline 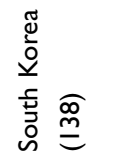 & 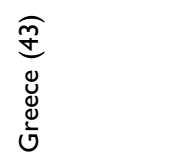 & 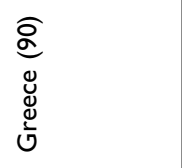 & 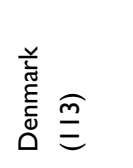 \\
\hline 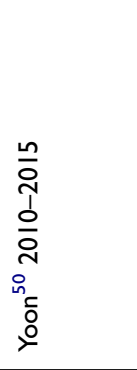 & 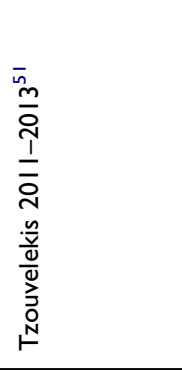 & 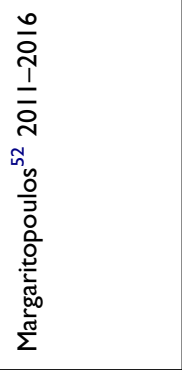 & 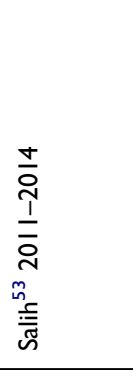 \\
\hline
\end{tabular}

\section{Pirfenidone and Patient Reported Outcome Measures (PROMs)}

Cough and dyspnea are the most incapacitating symptoms experienced by patients with IPF. ${ }^{27}$ An observational study of 43 IPF patients assessed the effect of pirfenidone on cough and cough-related quality of life (QoL) in patients with IPF. All patients underwent baseline 24-h cough recording with the Leicester Cough Monitor, which is a validated ambulatory cough monitoring system, prior to starting pirfenidone, and then after 4 and 12 weeks of treatment. After 12 weeks of treatment, $74 \%$ patients reported subjective improvement in cough and the objective $24-\mathrm{h}$ cough decreased by $34 \%$ as measured by Leicester cough monitor. This was the first study showing clinically meaningful improvement in cough with pirfenidone. ${ }^{28}$

Dyspnea is now recognized as the most important factor for determining health-related quality of life in patients with IPF and is more likely to worsen in patients with more severe disease versus less severe disease. Post hoc analysis of all the three phase -3 trials has recently showed that treatment with pirfenidone slows the worsening of patientreported breathlessness over 12 months vs placebo in patients with more advanced disease (FVC $<80 \%)$ as measured by University of San Diego Shortness of Breath Questionnaire (UCSD-SOBQ) ${ }^{29}$ Further research is needed to examine the effects of pirfenidone on IPF-related symptoms and patient-related outcome measures.

\section{Dosing and Tolerability of Pirfenidone}

The recommended dose for Pirfenidone is $2403 \mathrm{mg} /$ day in three divided doses to be taken with meals. Coadministration of food is thought to reduce gastrointestinal side effects by reducing the maximum plasma concentration of the drug. ${ }^{30}$ Pirfenidone has a well-characterized safety profile and is generally well tolerated. Most common side effects are gastrointestinal and photosensitivity, and most common laboratory abnormality is the elevation in transaminases. These side effects generally lead to temporary dose reductions or interruptions and in some cases, permanent discontinuation of the drug. ${ }^{31,32}$ However, many patients are unable to tolerate the full dose due to the above-listed side effects. The reduction in the rate of FVC decline is thought to be dose dependent and could be affected by dose reductions. ${ }^{5}$ There is limited data on the efficacy and tolerability of pirfenidone at lower doses.

Nathan et al recently conducted a post hoc analysis of ASCEND and CAPACITY 004/006 trials to evaluate the 
effect of pirfenidone dose reductions and interruptions on the annual rate of FVC decline. ${ }^{31}$ Patients in pirfenidone and placebo groups were stratified using a dose intensity threshold (DI) of $>90 \%$ or $<90 \%$. DI was calculated as the actual total drug dose a patient received divided by the planned dose $(2403 \mathrm{mg} /$ day for the entire study duration). There were no significant differences in the baseline characteristics of patients in DI $>90 \%$ and $\mathrm{DI}<90 \%$ groups in both, pirfenidone and placebo arms. Majority of the dose interruptions occurred in the first 6 months and more patients receiving pirfenidone had permanent dose reductions as compared to those receiving placebo ( $31.5 \%$ vs $20.8 \%$, respectively).

The study showed that the annual rate of FVC decline and proportion of patients experiencing death at 12 months or $>50 \mathrm{~m}$ decline in 6MWD were lower in pirfenidone group as compared to placebo group in both $\mathrm{DI}>90 \%$ and $\mathrm{DI}<90 \%$ groups. However, the relative difference of patients who experienced decline FVC or death who were randomized to receive placebo or pirfenidone was $-33.1 \%$ in the $\leq 90 \%$ DI and $-54.8 \%$ in the $>90 \%$ DI, with a greater difference observed in the $>90 \%$ DI. ${ }^{31}$

The results from this post hoc analysis demonstrated treatment benefit at different dosing intensities and hence, supports the approach of dose modification as a tool to reduce the rate of treatment discontinuation. However, the minimum dose of pirfenidone required through the modification period to maintain efficacy is still unknown. A recent report from Japan suggests that pirfenidone dose adjustment by body surface area in patients with IPF could be adequate to prevent adverse effects while achieving efficacy and treatment effect. ${ }^{33}$

Age is an important factor in determining the tolerability of pirfenidone. Recent study from Japan has shown that amongst a group of 120 IPF patients, the rate of drug discontinuation at 1 year was $29 \%$ higher in elderly patients (>75 years) when compared with the younger age group $\left(<75\right.$ years) ${ }^{34}$ In regards to the adverse events, gastrointestinal side effects and discontinuation of drug due to gastrointestinal disorders were significantly higher in elderly patients as compared to younger patients $(77 \%$ vs $45 \%$, p $0.007 ; 35 \%$ vs $15 \%$, $\mathrm{p}=0.019$, respectively). ${ }^{34}$

\section{Safety Profile of Pirfenidone}

\section{Treatment Emergent Side Effects in Phase} III Trials

The most commonly reported adverse effects in the CAPACITY and ASCEND trials were gastrointestinal and skin related. Gastrointestinal events reported in the pirfenidone $(\mathrm{n}=623)$ and placebo $(\mathrm{n}=624)$ groups, respectively, were diarrhea $(18.8 \%$ vs $14.4 \%)$, nausea ( $32.4 \%$ vs $12.2 \%)$, and dyspepsia ( $16.1 \%$ vs $5 \%)$. Skin events reported in the pirfenidone and placebo groups, respectively, were photosensitivity $(9.3 \%$ vs $1.1 \%)$ and rash $(26.2 \%$ vs $7.7 \%)$. Both, gastrointestinal and dermatologic adverse events, were generally mild to moderate and reversible. Only 9 (1.7\%) patients discontinued pirfenidone treatment due to gastrointestinal adverse events and 12 $(1.9 \%)$ due to skin-related adverse events. ${ }^{5,6,15,35}$

Table 2 shows the most common side effects experienced by patients in Phase 3 trials. Most common laboratory abnormality was elevated transaminases in the pirfenidone group (14.4\%), which normalized after discontinuation of the drug.

\section{RECAP}

RECAP was an open-label extension study to evaluate drug safety in patients who completed CAPACITY and

Table 2 Adverse Drug Reactions in Phase III Trials

\begin{tabular}{|l|l|l|l|l|}
\hline \multirow{2}{*}{ Side Effect } & \multicolumn{2}{l|}{ CAPACITY 004/006 Trials $^{\mathbf{5}}$} & \multicolumn{2}{l|}{ ASCEND Trial } \\
\cline { 2 - 5 } & Pirfenidone (n=345) & Placebo (n=347) & Pirfenidone (n= 278) & Placebo (n=277) \\
\hline Nausea & $125(36 \%)$ & $60(17 \%)$ & $100(36 \%)$ & $37(13.4 \%)$ \\
Dyspepsia & $66(19 \%)$ & $26(7 \%)$ & $49(17.6 \%)$ & $17(6.1 \%)$ \\
Dizziness & $63(18 \%)$ & $35(10 \%)$ & $49(17.6 \%)$ & $36(13 \%)$ \\
Vomiting & $47(14 \%)$ & $15(4 \%)$ & $36(12.9 \%)$ & $24(8.7 \%)$ \\
Rash/photosensitivity & $153(44 \%)$ & $46(14 \%)$ & $78(28.1 \%)$ & $24(8.7 \%)$ \\
Anorexia & $37(11 \%)$ & $13(4 \%)$ & $44(15.8 \%)$ & $18(6.5 \%)$ \\
Arthralgia & $36(10 \%)$ & $24(7 \%)$ & - & - \\
Weight reduction & $28(8 \%)$ & $12(3 \%)$ & $35(12.6 \%)$ & $22(7.9 \%)$ \\
Insomnia & $34(10 \%)$ & $23(7 \%)$ & $31(11.2 \%)$ & $18(6.5 \%)$ \\
Cough & - & - & $70(25.2 \%)$ & $82(29.6 \%)$ \\
\hline
\end{tabular}


ASCEND trials. It followed 1058 patients for 7 years, of which $40.4 \%$ completed the study. Adverse drug reactions were reported by 786 patients $(74.3 \%)$. The most frequent adverse drug reactions were nausea $(21.6 \%)$, diarrhea $(12.3 \%)$, and rash $(11.6 \%)$. Discontinuation of treatment due to an adverse drug reaction occurred in 120 patients $(11.3 \%)$ and the most common reaction leading to discontinuation was rash and nausea. ${ }^{15}$

In contrast to the ASCEND and CAPACITY trials, the frequency and adjusted rate of adverse drug reactions were, in fact, lower in RECAP study $(74.3 \%$ vs $89.2 \%)$, which in part can be attributed to positive selection bias. ${ }^{15}$

\section{PASSPORT - Pirfenidone Post- Authorization Safety Registry}

PASSPORT was a multicenter, post-authorization, and prospective study of IPF patients $(n=1009)$ who were newly prescribed pirfenidone and followed for 2 years thereafter. The aim of the study to evaluate long-term safety of pirfenidone. Median pirfenidone exposure was 442.0 days. Overall, 73.4\% patients experienced adverse drug reaction, most commonly gastrointestinal symptoms (38.3\%), photosensitivity/rash (29\%), nausea (20.6\%) and fatigue (18.5\%). These adverse events led to treatment discontinuation in $28.7 \%$ of patients. Older age, use of steroids prior to the study and female sex were associated with early treatment discontinuation. These adverse drug reactions also led to dose adjustment in $48.3 \%$ of patients. More patients completed treatment following a dose adjustment than those who had no dose adjustment (38.8 vs $26.1 \%$, respectively).

Overall, the study showed similar side effect profile of pirfenidone in the post-marketing era as in the clinical trials. It also showed that dose adjustment had a favorable effect on treatment persistence. ${ }^{32}$

\section{Real-World Experience}

There is emerging data from various single and multicenters on the safety and tolerability profile of pirfenidone in IPF patients. So far, the safety profile of pirfenidone is consistent across all groups of IPF patients. These findings are summarized in Table 1.

\section{Prevention and Management of Pirfenidone Related Side Effects}

Dose titration and modification protocols have been shown to be effective in reducing discontinuation rates due to gastrointestinal discomfort. ${ }^{31}$ A 2-week dose titration schedule has been recommended by the manufacturing company. $^{36}$ In LOTUSS trial, a longer 4-week titration schedule was compared with the standard 2-week titration schedule in patients with scleroderma ILD to test the safety and tolerability of pirfenidone. The longer 4-week titration schedule was shown to have less dose modifications and dose interruptions as compared to standard 2-week titration (21.9 vs $3.2, \mathrm{p}=0.053 ; 12.5 \%$ vs $0 \%$, $\mathrm{p}=0.113$, respectively). ${ }^{37}$ The two titration schedules are listed in Table 4. Strategies to manage common extragastrointestinal side effects are listed in Table 3

\section{Pirfenidone and Nintedanib}

Nintedanib is the other anti-fibrotic drug approved for treatment for IPF. ${ }^{7}$ It is an intracellular inhibitor and targets multiple tyrosine kinases, such as the VEGF, FGF, and PDGF receptors. ${ }^{38}$ Nintedanib was shown to reduce decline

Table 3 Prevention and Management of Pirfenidone Related Side Effects

\begin{tabular}{|l|l|}
\hline $\begin{array}{l}\text { Adverse } \\
\text { Event }\end{array}$ & Prevention and Management \\
\hline General & Dose reduction/interruptions \\
\hline Rash & $\begin{array}{l}\text { Discontinue until rash resolves and re-start at a slow titration schedule. } \\
\text { Permanently discontinue if rash recurs }\end{array}$ \\
\hline Photosensitivity & $\begin{array}{l}\text { Prevention with continuous skin protection with clothing and SPF-50 sunscreen Treat severe reaction with steroids or silver } \\
\text { sulfadiazine Permanently discontinue if an allergic reaction occurs }\end{array}$ \\
\hline Transaminitis & $\begin{array}{l}\text { If AST and ALT elevations are }>3 \text { to } \leqslant 5 \text { ULN without symptoms or hyperbilirubinaemia, reduce the dose or interrupt until values } \\
\text { return to normal. If AST and ALT elevations are }>3 \text { to } \leqslant 5 \text { ULN and accompanied by hyperbilirubinaemia, permanently } \\
\text { discontinue pirfenidone. If AST or ALT are }>5 \text { ULN, permanently discontinue pirfenidone }\end{array}$ \\
\hline Gastrointestinal & Dose reduction or interruption with a slow titration back to full dose as tolerated Use of PPI Take medication with a substantial meal \\
\hline
\end{tabular}

Abbreviations: AST, aspartate aminotransferase; ALT, alanine aminotransferase; ULN, upper limit of normal; PPI, proton pump inhibitors. 
Table 4 Pirfenidone Dose Titration Protocol

\begin{tabular}{|l|l|}
\hline \multicolumn{2}{|l|}{ Pirfenidone Titration Schedule } \\
\hline 2-week titration schedule \\
\hline Titration interval & Dosing (Total number of pills per day) \\
\hline $\begin{array}{l}\text { Days I-7 } \\
\text { Days 8-14 }\end{array}$ & $\begin{array}{l}\text { I tablet TID (3) } \\
\text { Days }>\text { tablets TID (6) } \\
\text { 4-week titration schedule }\end{array}$ \\
\hline Titration interval & Dosing (Total number of pills per day) \\
\hline $\begin{array}{l}\text { Days I-14 } \\
\text { Days I5-28 }\end{array}$ & I tablet TID (3) \\
Days $>29$ & 3 tablets TID (6) \\
\hline
\end{tabular}

Note: *Full dose.

in FVC in IPF patients as compared to the placebo group in both, INPULSIS I $(-114.7 \mathrm{~mL}$ vs $-239.9 \mathrm{~mL}, \mathrm{p}<0.001)$ and INPULSIS II $(-113.6 \mathrm{~mL}$ VS $-207.3 \mathrm{~mL}, \mathrm{p}<0.001)$ over 52 weeks. $^{7}$ The most common side effect of nintedanib was diarrhea with incidence as high as 63\%; however, the rate of permanent discontinuation due to diarrhea is reported to be less than $10 \%$ in clinical trials and real-world data. ${ }^{39}$ In both the INPULSIS trials, the proportion of patients with serious adverse events was similar in the nintedanib and placebo groups. However, nintedanib group had higher rates of myocardial infarction as compared to the placebo group in both INPULSIS I ( $1.6 \%$ vs $0.5 \%)$ and II trials ( $1.5 \%$ vs $0.5 \%)$. A recent post hoc analyses of TOMORROW and INPULISIS clinical trials showed that the incidence of myocardial infarction was higher in the nintedanib group than the placebo group among patients with higher cardiovascular risk, whereas the incidence rate of other ischemic heart disease was lower in the nintedanib group than the placebo group. ${ }^{40}$ The clinical significance of this finding remains unknown.

There are no trials directly comparing pirfenidone and nintedanib in IPF patients. Both the drugs have been shown to be effective in reducing the lung function decline in IPF patients when compared to placebo. Observation studies have shown comparable tolerability and efficacy of these agents and now new safety signals have been identified. ${ }^{39,41,42}$

\section{Conclusion}

Pirfenidone slows disease progression in IPF and likely improves survival, decreases the rate of respiratory-related hospitalizations and improves PROMs. It is generally well tolerated and has few known interactions with commonly prescribed drugs. Gastrointestinal and photosensitivity are the most frequently experienced side effects and are usually managed by dose reductions, which in turn can decrease the effectiveness of the drug. In real-world experience, most sites have reported treatment discontinuation rates to be around $10-20 \%$. Discontinuation rates can be higher in elderly patients and dose modification is now recognized as an important tool to maintain medication compliance and minimize side effects.

In conclusion, pirfenidone is an anti-fibrotic drug that is a viable, well-tolerated, real-world option for the treatment of patients with IPF.

\section{Disclosure}

Tracy R Luckhardt reports personal fees from Boehringer Ingelheim and France Foundation, outside the submitted work. The authors report no other conflicts of interest in this work.

\section{References}

1. Raghu G, Remy-Jardin M, Myers JL, et al. Diagnosis of idiopathic pulmonary fibrosis. An official ATS/ERS/JRS/ALAT clinical practice guideline. Am J Respir Crit Care Med. 2018;198(5):e44-e68. doi:10.1164/rccm.201807-1255ST

2. Raghu G, Chen S-Y, Yeh W-S, et al. Idiopathic pulmonary fibrosis in US medicare beneficiaries aged 65 years and older: incidence, prevalence, and survival, 2001-11. Lancet Respir Med. 2014;2 (7):566-572. doi:10.1016/S2213-2600(14)70101-8

3. Ley B, Collard HR, King TE. Clinical course and prediction of survival in idiopathic pulmonary fibrosis. Am J Respir Crit Care Med. 2011;183(4):431-440. doi:10.1164/rccm.201006-0894CI

4. Collard HR, Ryerson CJ, Corte TJ, et al. Acute exacerbation of idiopathic pulmonary fibrosis. An international working group report. Am J Respir Crit Care Med. 2016;194(3):265-275. doi:10.1164/rccm.201604-0801CI

5. Noble PW, Albera C, Bradford WZ, et al. Pirfenidone in patients with idiopathic pulmonary fibrosis (CAPACITY): two randomised trials. Lancet Lond Engl. 2011;377(9779):1760-1769. doi:10.1016/S01406736(11)60405-4

6. King TE, Bradford WZ, Castro-Bernardini S, et al. A phase 3 trial of pirfenidone in patients with idiopathic pulmonary fibrosis. $N \mathrm{Engl}$ J Med. 2014;370(22):2083-2092. doi:10.1056/NEJMoa1402582

7. Richeldi L, Du Bois RM, Raghu G, et al. Efficacy and safety of nintedanib in idiopathic pulmonary fibrosis. $N$ Engl J Med. 2014;370 (22):2071-2082. doi:10.1056/NEJMoa1402584

8. Conte E, Gili E, Fagone E, Fruciano M, Iemmolo M, Vancheri C. Effect of pirfenidone on proliferation, TGF- $\beta$-induced myofibroblast differentiation and fibrogenic activity of primary human lung fibroblasts. Eur J Pharm Sci off J Eur Fed Pharm Sci. 2014;58:13-19. doi:10.1016/j.ejps.2014.02.014

9. Oku H, Shimizu T, Kawabata T, et al. Antifibrotic action of pirfenidone and prednisolone: different effects on pulmonary cytokines and growth factors in bleomycin-induced murine pulmonary fibrosis. Eur J Pharmacol. 2008;590(1-3):400-408. doi:10.1016/j.ejphar.2008.06.046

10. Nathan SD, Albera C, Bradford WZ, et al. Effect of pirfenidone on mortality: pooled analyses and meta-analyses of clinical trials in idiopathic pulmonary fibrosis. Lancet Respir Med. 2017;5(1):33-41. doi:10.1016/S2213-2600(16)30326-5 
11. Azuma A, Nukiwa T, Tsuboi E, et al. Double-blind, placebo-controlled trial of pirfenidone in patients with idiopathic pulmonary fibrosis. Am J Respir Crit Care Med. 2005;171 (9):1040-1047. doi:10.1164/rccm.200404-5710C

12. Taniguchi H, Ebina M, Kondoh Y, et al. Pirfenidone in idiopathic pulmonary fibrosis. Eur Respir J. 2010;35(4):821-829. doi:10.1183/ 09031936.00005209

13. Noble PW, Albera C, Bradford WZ, et al. Pirfenidone for idiopathic pulmonary fibrosis: analysis of pooled data from three multinational phase 3 trials. Eur Respir J. 2016;47(1):243-253. doi:10.1183/ 13993003.00026-2015

14. Nathan SD, Albera C, Bradford WZ, et al. Effect of continued treatment with pirfenidone following clinically meaningful declines in forced vital capacity: analysis of data from three phase 3 trials in patients with idiopathic pulmonary fibrosis. Thorax. 2016;71 (5):429-435. doi:10.1136/thoraxjnl-2015-207011

15. Costabel U, Albera C, Lancaster LH, et al. An open-label study of the long-term safety of pirfenidone in patients with idiopathic pulmonary fibrosis (RECAP). Respir Int Rev Thorac Dis. 2017;94(5):408-415. doi: $10.1159 / 000479976$

16. Costabel U, Albera C, Glassberg MK, et al. Effect of pirfenidone in patients with more advanced idiopathic pulmonary fibrosis. Respir Res. 2019;20(1):55. doi:10.1186/s12931-019-1021-2

17. Zurkova M, Kriegova E, Kolek V, et al. Effect of pirfenidone on lung function decline and survival: 5-yr experience from a real-life IPF cohort from the Czech EMPIRE registry. Respir Res. 2019;20(1):16. doi:10.1186/s12931-019-0977-2

18. Agarwal R, Jindal SK. Acute exacerbation of idiopathic pulmonary fibrosis: a systematic review. Eur J Intern Med. 2008;19(4):227-235. doi:10.1016/j.ejim.2007.04.024

19. Bafadhel M, McKenna S, Terry S, et al. Acute exacerbations of chronic obstructive pulmonary disease: identification of biologic clusters and their biomarkers. Am $J$ Respir Crit Care Med. 2011;184(6):662-671. doi:10.1164/rccm.201104-0597OC

20. Natsuizaka M, Chiba H, Kuronuma K, et al. Epidemiologic survey of Japanese patients with idiopathic pulmonary fibrosis and investigation of ethnic differences. Am J Respir Crit Care Med. 2014;190 (7):773-779. doi:10.1164/rccm.201403-0566OC

21. Raghu G, Collard HR, Egan JJ, et al. An official ATS/ERS/JRS/ ALAT statement: idiopathic pulmonary fibrosis: evidence-based guidelines for diagnosis and management. Am J Respir Crit Care Med. 2011;183(6):788-824. doi:10.1164/rccm.2009-040GL

22. Gaudry S, Vincent F, Rabbat A, et al. Invasive mechanical ventilation in patients with fibrosing interstitial pneumonia. $J$ Thorac Cardiovasc Surg. 2014;147(1):47-53. doi:10.1016/j.jtcvs.2013.06.039

23. Vianello A, Arcaro G, Battistella L, et al. Noninvasive ventilation in the event of acute respiratory failure in patients with idiopathic pulmonary fibrosis. J Crit Care. 2014;29(4):562-567. doi:10.1016/j. jcrc.2014.03.019

24. Ley B, Swigris J, Day B, et al. Pirfenidone reduces respiratory-related hospitalizations in idiopathic pulmonary fibrosis Am J Respir Crit Care Med. 2017;196(6):756-761. doi:10.1164/ rccm.201701-00910C

25. Furuya K, Sakamoto S, Shimizu H, et al. Pirfenidone for acute exacerbation of idiopathic pulmonary fibrosis: a retrospective study. Respir Med. 2017;126:93-99. doi:10.1016/j.rmed.2017.03.026

26. Kataoka K, Taniguchi H, Kondoh Y, et al. Recombinant human thrombomodulin in acute exacerbation of idiopathic pulmonary fibrosis. Chest. 2015;148(2):436-443. doi:10.1378/chest.14-2746

27. van Manen MJG, Birring SS, Vancheri C, et al. Cough in idiopathic pulmonary fibrosis. Eur Respir Rev off J Eur Respir Soc. 2016;25 (141):278-286. doi:10.1183/16000617.0090-2015

28. van Manen MJG, Birring SS, Vancheri C, et al. Effect of pirfenidone on cough in patients with idiopathic pulmonary fibrosis. Eur Respir J. 2017;50:4. doi:10.1183/13993003.01157-2017
29. Glassberg MK, Wijsenbeek MS, Gilberg F, Petzinger U, Kirchgaessler K-U, Albera C. Effect of pirfenidone on breathlessness in patients with idiopathic pulmonary fibrosis. Eur Respir J. 2019;54:1900399. doi:10.1183/13993003.00399-2019

30. Rubino CM, Bhavnani SM, Ambrose PG, Forrest A, Loutit JS. Effect of food and antacids on the pharmacokinetics of pirfenidone in older healthy adults. Pulm Pharmacol Ther. 2009;22(4):279-285. doi:10.10 16/j.pupt.2009.03.003

31. Nathan SD, Lancaster LH, Albera C, et al. Dose modification and dose intensity during treatment with pirfenidone: analysis of pooled data from three multinational phase III trials. BMJ Open Respir Res. 2018;5(1):e000323. doi:10.1136/bmjresp-2018-000323

32. Cottin V, Koschel D, Günther A, et al. Long-term safety of pirfenidone: results of the prospective, observational PASSPORT study. ERJ Open Res. 2018;4:4. doi:10.1183/23120541.00084-2018

33. Uehara M, Enomoto N, Karayama M, et al. Evaluation of pirfenidone dose adjusted by body weight or body surface area in the treatment for Japanese patients with interstitial pneumonia. In: C38. UNDERSTANDING THERAPEUTICS IN IPF. American Thoracic Society International Conference Abstracts. American Thoracic Society; 2017:6A5401-A5401. doi:10.1164/ajrccm-conference. 2017.195.1_MeetingAbstracts.A5401

34. Sakayori $\bar{M}$, Terada J, Abe M, et al. Differences in tolerability of pirfenidone between elderly and younger patients with idiopathic pulmonary fibrosis. Drug Des Devel Ther. 2019;13:2295-2303. doi:10.2147/DDDT.S208733

35. Side effects and safety data $\mid$ esbriet $^{\circledR}$ (pirfenidone) HCP. Available from: https://www.esbriethcp.com/safety-tolerability-dosing/safetytolerability.html. Accessed July 2, 2019.

36. Lederer DJ, Martinez FJ, Longo DL. Idiopathic pulmonary fibrosis. $N$ Engl J Med. 2018;378(19):1811-1823. doi:10.1056/NEJMra17 05751

37. Khanna D, Albera C, Fischer A, et al. An open-label, phase II study of the safety and tolerability of pirfenidone in patients with scleroderma-associated interstitial lung disease: the LOTUSS trial. $J$ Rheumatol. 2016;43(9):1672-1679. doi:10.3899/jrheum.151322

38. Chaudhary NI, Roth GJ, Hilberg F, et al. Inhibition of PDGF, VEGF and FGF signalling attenuates fibrosis. Eur Respir J. 2007;29 (5):976-985. doi:10.1183/09031936.00152106

39. Noth I, Oelberg D, Kaul M, Conoscenti CS, Raghu G. Safety and tolerability of nintedanib in patients with idiopathic pulmonary fibrosis in the USA. Eur Respir J. 2018;52:1. doi:10.1183/1399300 3.02106-2017

40. Noth I, Wijsenbeek M, Kolb M, et al. Cardiovascular safety of nintedanib in subgroups by cardiovascular risk at baseline in the TOMORROW and INPULSIS trials. Eur Respir J. 2019;54:3. doi:10.1183/13993003.01797-2018

41. Barratt SL, Mulholland S, Al Jbour K, et al. South-West of England's experience of the safety and tolerability pirfenidone and nintedanib for the treatment of Idiopathic Pulmonary Fibrosis (IPF). Front Pharmacol. 2018;9:1480. doi:10.3389/fphar.2018.01480

42. Okuda R, Hagiwara E, Baba T, Kitamura H, Kato T, Ogura T. Safety and efficacy of pirfenidone in idiopathic pulmonary fibrosis in clinical practice. Respir Med. 2013;107(9):1431-1437. doi:10.1016/j. rmed.2013.06.011

43. Wijsenbeek MS, Van Beek FT, Geel AL, et al. Pirfenidone in daily clinical use in patients with idiopathic pulmonary fibrosis in the Netherlands. In: C48. INTERSTITIAL LUNG DISEASE: OUTCOMES, TREATMENT, AND EXACERBATION. American Thoracic Society International Conference Abstracts. American Thoracic Society; 2013:A4340. doi:10.1164/ajrccm-conference. 2013.187.1_MeetingAbstracts.A4340

44. Ravaglia C, Gurioli C, Romagnoli M, et al. Pirfenidone treatment in idiopathic pulmonary fibrosis: an Italian case series. Eur Respir J. 2013;42(Suppl 57):P3370. 
45. Bonella F, Wessendorf TE, Costabel U. Clinical experience with pirfenidone for the treatment of idiopathic pulmonary fibrosis. Dtsch Med Wochenschr. 2013;138(11):518-523. doi:10.1055/ s-0032-1332930

46. Arai T, Inoue Y, Sasaki Y, et al. Predictors of the clinical effects of pirfenidone on idiopathic pulmonary fibrosis. Respir Investig. 2014;52(2):136-143. doi:10.1016/j.resinv.2013.09.002

47. Oltmanns U, Kahn N, Palmowski K, et al. Pirfenidone in idiopathic pulmonary fibrosis: real-life experience from a German tertiary referral center for interstitial lung diseases. Respir Int Rev Thorac Dis. 2014;88(3):199-207. doi:10.1159/000363064

48. Chaudhuri N, Duck A, Frank R, Holme J, Leonard C. Real world experiences: pirfenidone is well tolerated in patients with idiopathic pulmonary fibrosis. Respir Med. 2014;108(1):224-226. doi:10.1016/j. rmed.2013.11.005

49. Hanta I, Cilli A, Sevinc C. The effectiveness, safety, and tolerability of pirfenidone in idiopathic pulmonary fibrosis: a retrospective study. Adv Ther. 2019;36(5):1126-1131. doi:10.1007/s12325-01900928-3
50. Yoon H-Y, Kim DS, Song JW. Efficacy and safety of pirfenidone in advanced idiopathic pulmonary fibrosis. Respir Int Rev Thorac Dis. 2019;97(3):242-251. doi:10.1159/000492937

51. Tzouvelekis A, Ntolios P, Karampitsakos T, et al. Safety and efficacy of pirfenidone in severe idiopathic pulmonary fibrosis: a real-world observational study. Pulm Pharmacol Ther. 2017;46:48-53. doi:10.1016/j.pupt.2017.08.011

52. Margaritopoulos GA, Trachalaki A, Wells AU, et al. Pirfenidone improves survival in IPF: results from a real-life study. BMC Pulm Med. 2018;18(1):177. doi:10.1186/s12890-018-0736-z

53. Salih GN, Shaker SB, Madsen HD, Bendstrup E. Pirfenidone treatment in idiopathic pulmonary fibrosis: nationwide Danish results. Eur Clin Respir J. 2016;3:32608. doi:10.3402/ecrj.v3.32608

54. Esbriet ${ }^{\circledR}$ (pirfenidone) information for healthcare professionals. Available from: https://www.esbriethcp.com/index.html?c=esb-1631d3792bb\&gclid= Cj0KCQiAgebwBRDnARIsAE3eZjT6zHuuSFTLEn1qp7upWzTKgjKDQ bbrrOH5Fs0oOdnV8vnQisd4J3YaAqsjEALw_wcB\&gclsrc=aw.ds. Accessed January 11, 2020.

\section{Publish your work in this journal}

Drug, Healthcare and Patient Safety is an international, peer-reviewed open-access journal exploring patient safety issues in the healthcare continuum from diagnostic and screening interventions through to treatment, drug therapy and surgery. The journal is characterized by the rapid reporting of reviews, original research, clinical, epidemiological and post-marketing surveillance studies, risk management, health literacy and educational programs across all areas of healthcare delivery. The manuscript management system is completely online and includes a very quick and fair peer-review system. Visit http://www.dovepress.com/testimonials.php to read real quotes from published authors. 